\title{
The contribution of ethology and evolutionary biology in
} neurosciences

\author{
Magdalini Krommyda*1, Myrto Kamari ${ }^{1}$, Athanasios Gousiopoulos ${ }^{1}$, \\ Manos Kontakis ${ }^{1}$, Konstantinos Fountoulakis ${ }^{2}$, Vasileios Petridis ${ }^{1}$ and \\ George Kaprinis ${ }^{2}$
}

\author{
Address: ${ }^{1}$ Aristotle University of Thessaloniki, Greece and ${ }^{23 r d}$ Department of Psychiatry, AHEPA Hospital, Aristotle University of Thessaloniki, \\ Greece \\ * Corresponding author
}

from International Society on Brain and Behaviour: 2nd International Congress on Brain and Behaviour

Thessaloniki, Greece. 17-20 November 2005

Published: 28 February 2006

Annals of General Psychiatry 2006, 5(Suppl I):S250 doi:I0.II86/I744-859X-5-SI-S250

\section{Background}

According to the general biological theory the development and evolution of humans into complete bio-psychosocial beings are realized through continuous morphological and functional adjustment processes. The basic goals of these processes are (a) survival in all the different types of environment that the individual is confronted with, and (b) assurance of the continuation of the species via the succession of its generations. In this evolutionary biological theory and in agreement with the value of observing behaviours lie also the roots of ethology.

\section{Materials and methods}

Ethology mainly studies the behaviour of animals in their natural settings, trying to describe which behavioural traits are inherited and which are acquired as time passes and experiences are earned. By using non-experimental, observational techniques ethologists try to approach both nonverbal and verbal behavioural patterns, as well as the communicative aspects of each. Their study is based on the comparative method and phylogenetic assumptions. Moreover, new scientific subsections like neuroethology, which is particularly interested in the neural basis of naturally occurring animal behaviour and socio-biology have evolved. In a similar manner, evolutionary biology studies human behaviour by concentrating on the transmission and modification of genetically influenced behavioural traits and the mechanisms regulating these traits: development, function and the environment.

\section{Results}

Many interesting results highlight the importance of ethology and evolutionary biology to medicine as far as their special relevance to neurosciences is concerned. Primary examples are the studies of imprinting in newly hatched goslings and the practical function of aggression such as the defense of their territory by fish and birds by Konrad Lorenz. Tinbergen's discovery of so-called displacement activities and Von Frisce's analyses of how bees communicate with each other represent other key contributions. Animal models, such as the panic of some monkeys that have never been exposed previously to snakes when placed in the presence of a snake, have also been used in the study of phobic responses. Moreover, certain human neuro-endocrine mechanisms such as the pathological substrate in insulin secretion in type 2 diabetes and the sodium-sensitive type of hypertension can be approached under a different scope in the framework of evolutionary biology.

\section{Discussion}

Evolutionary studies of human behaviour prove that a more accurate knowledge of behaviour and the needs shaped by natural selection can significantly reduce mental suffering and improve psychological well-being. Because of the influence of genetic information on traits, humans, like other species, enter the world predisposed to process and interpret information in species-typical ways, to engage in certain behaviours and to achieve specific goals. Genetic influences may also play a role in the development of phobias, since some human phobic responses may represent exaggerations of adaptive behaviours 
formed by evolutionary biology. Through evolutionary biology, human behavioural characteristics and also basic neuro-endocrine mechanisms can be investigated from a different angle allowing a more thorough understanding of the phylogenetic evolution of all organisms.

\section{References}

I. Kaprinis G, Fountoulakis K: Complementary reading for the module "Structure and Function of the Central Nervous System". In Comprehensive Textbook of Psychiatry 7th edition. Edited by: Sadock BJ, Sadock VA. Philadelphia: Lippincott Williams and Wilkins; 2000:484-562.

2. Keeley B: Neuroethology and the philosophy of cognitive science. Philosophy of Science 1998, 67:404-417.

3. Marler P: Ethology and the origins of behavioral endocrinology. Hormones and Behavior 2005, 47:493-502.

Publish with Biomed Central and every scientist can read your work free of charge

"BioMed Central will be the most significant development for disseminating the results of biomedical research in our lifetime. "

Sir Paul Nurse, Cancer Research UK

Your research papers will be:

- available free of charge to the entire biomedical community

- peer reviewed and published immediately upon acceptance

- cited in PubMed and archived on PubMed Central

- yours - you keep the copyright

Submit your manuscript here:

http://www.biomedcentral.com/info/publishing_adv.asp 